\title{
GRAVITATING TOWARDS STABILITY: GUIDOBALDO'S ARISTOTELIAN-ARCHIMEDEAN SYNTHESIS
}

\author{
Maarten Van Dyck \\ Ghent University
}

\section{INTRODUCTION: TRADITIONS IN THE HISTORY OF SCIENCE}

Until recently, Guidobaldo del Monte (1545-1607) was treated mainly as a transitional figure in the history of science. His contributions to the revival of the ancient science of mechanics were often praised, whilst his inability to see beyond the ancients was much deplored. Whereas Pierre Duhem's derisory description of Guidobaldo's æeuvre as "sometimes in error, always mediocre" found its direct echo in the work of the French historians of science Pierre Costabel and René Dugas, ${ }^{2}$ Anglo-Saxon historians of science tended to be somewhat more positive in their judgement. Yet both Paul Lawrence Rose and Stillman Drake, to name but two of the most prominent, did not truly alter Duhem's assessment. ${ }^{3}$ They admitted that Guidobaldo's work contributed to the advance of modern science, since he was one of the most influential promoters of a mathematical approach to nature and most importantly an early supporter of Galileo, ${ }^{4}$ but they still stressed the many steps he was unable to take which "he would otherwise have been quite capable of making". 5

It is clear that these negative evaluations of Guidobaldo's mechanical writings are based on a particular historiographical position that favours the vantage point of 'classical' mechanics as a norm by which to judge earlier approaches. Accordingly, it is not surprising that in more recent literature we find important amendments to this picture. ${ }^{6}$ By focusing more closely on Guidobaldo's own interests and predicament, these writers have stressed the social position from which he was working, the philosophical and scientific agendas he was pursuing, and especially the interplay between these elements. As a result, we are beginning to have a more nuanced understanding of the reasons why Guidobaldo's mechanics has some of the particular characteristics for which he was so severely criticized by earlier writers.

Much of the (admittedly not very numerous) writings on Guidobaldo's mechanics have been organized around the historiographical categories of scientific traditions or schools. Drake influentially but controversially distinguished two sixteenth-century Italian schools of mechanics: a Northern group, "conspicuously interested in practical aspects of mechanics", and a Central Italian group that "concentrated its interest on works of classical antiquity and on the rigorous application of mathematics to mechanics". ${ }^{7}$ While not questioning the difference in outlook between these groups of mathematicians, Mario Biagioli has tried to "uncover the more complex social dimensions of the interaction of these two 'schools' and of their quite different conceptual styles". ${ }^{8}$ Enrico Gamba and Vico Montebelli take a step further in thoroughly investigating the characteristics and context of the Central Italian group, which was 
actually organized around the duchy of Urbino. They especially stress Guidobaldo's commitment to the empirical character of mechanics, and link this with the presence of skilled instrument makers in Urbino. ${ }^{9}$ Domenico Bertoloni Meli asks us to question the existence of a coherent agenda existing within the Urbino 'school', by opposing Commandino to Guidobaldo on a number of central issues. ${ }^{10}$ Gianni Micheli points to the fact that Guidobaldo's humanist interest in recovering an ancient science cannot be analysed separately from his attempts to come to a rational understanding of mechanical phenomena, and vice versa. ${ }^{11}$ Mary Henninger-Voss, finally, has paid detailed attention to the ways in which Guidobaldo himself consciously tried to establish a tradition for mechanics, one that at the same time could be based on noble and universal principles, and remain valuable in local artisanal contexts. ${ }^{12}$

By focusing on the notion of a tradition, most of these writers have primarily paid attention to Guidobaldo's conception of what constitutes the identity of the science of mechanics. ${ }^{13}$ As such, there are almost no recent extended discussions of the conceptual structure of the science for which Guidobaldo sought to establish an identity. ${ }^{14}$ Admittedly, these are two sides of the same coin; but taking this metaphor literally, it might be time to turn the coin and take another look at the reverse side. I will therefore try to focus on the actual conceptualizations used by Guidobaldo, and only at the end of my analysis will I refer to his own pronouncements on the nature of mechanics. My primary aim will be to examine the use to which central concepts, such as 'centre of gravity', are put within the confines of Guidobaldo's texts. That is, I am in the first place interested in the coherence that Guidobaldo tried to forge for the domain of mechanics by arguing for a host of relations between different concepts that were somehow connected with the traditional ways of conceiving mechanical phenomena.

To my mind, there is no doubt that the utility of this kind of exercise in conceptual analysis is determined partly by the position occupied by Guidobaldo as an influential example that Galileo at some point might have tried to emulate in his own endeavours in the field of mechanics. Let me therefore first clarify how the present paper is situated with respect to the kind of work pioneered by Duhem, which also was focused on conceptual issues. Its primary aim is to investigate Guidobaldo's science as much as possible on its own terms. I will for example not posit the existence of a dynamic and a static tradition in mechanics, presumably deriving from Aristotle and Archimedes respectively, as is often done following the lead of Duhem. ${ }^{15}$ I will try rather to investigate how Guidobaldo himself interpreted and recuperated the writings of his predecessors. After all, it was only through the work of people like Guidobaldo that such a distinction gradually took a meaningful shape, and in any case it will turn out that it makes no good sense to read Guidobaldo's own writings through such a filter. ${ }^{16}$ Yet, in an important sense the work of historians like Duhem is still the starting point for my own analysis. Their criticisms did single out some of the most peculiar aspects of Guidobaldo's mechanics. As such they provide some kind of hermeneutic benchmarks from which we can start to reconstitute some of the coherence of Guidobaldo's own conceptualizations of mechanical phenomena. ${ }^{17}$ 
It is clear that a complete treatment cannot avoid shifting to and fro between the level of conceptual analysis and a broader analysis of the philosophical and social implications of Guidobaldo's 'scientific project'. Yet by basing myself as much as possible on a thorough analysis of Guidobaldo's use of certain central concepts, I hope to lay part of the groundwork for a richer understanding of this scientific project than can be attained by focusing primarily on social and philosophical factors. This need not be taken as reflecting a sceptical attitude towards the previously cited literature. On the contrary, I consider most of the insights reached there as completely compatible with my own analysis. But let me indicate in what respect I hope to add substantially to them. The most central issue surrounding Guidobaldo's scientific project is the relation between on the one hand his adherence to the principles and canons of Archimedean science, and on the other his attempts to integrate this within an Aristotelian framework. It is reasonably clear that such a project cannot be understood without taking into account how this was part of Guidobaldo's attempts at forging an interesting socio-professional identity for the practitioners of the noble science of mechanics, and it is undeniable that this limits possible choices to be made in developing such a science. However, we need not suppose the interaction to have been one-sided. It is highly plausible to assume that particular conceptual aspects of (Guidobaldo's interpretation of) both Archimedes's writings on equilibrium and the Aristotelian treatise on mechanics helped to shape the particular form this attempted synthesis took. It is the latter suggestion that provides the motivation behind the present paper.

One further element of great interest that I will try to uncover is the interplay between theoretical and empirical considerations that is characteristic of Guidobaldo's mechanical writings. I think it is time to clear up some serious misconceptions concerning Guidobaldo that have been often repeated, especially in the literature on Galileo. Noretta Koertge, for example, states in a very influential article on Galilean idealization that Guidobaldo's work exemplified a "pedantic empiricist program" that counselled historians "to give up looking for simple ideal laws and try instead to describe actual states of affairs, warts, and accidents and all, in hideous, complicated detail", whereas Galileo "was too good a physicist" to adopt it. ${ }^{18}$ William Wallace even goes as far as stating that Guidobaldo "had examined Archimedes' proof of the balance theorem and had rejected it for its lack of rigor". ${ }^{19}$ It would certainly have outraged Guidobaldo, an admirer of the work of his Greek Master, that someone could ascribe such a position to him. Both Koertge and Wallace are apparently misled by Guidobaldo's discussion of the complications that arise because of the fact that the lines of descent of weights hanging from a balance are not parallel but actually converge in the centre of the Earth. We will see that Guidobaldo's actual considered position on this matter is much more subtle that anyone has seen up till now. It is only when we are thus freed from ascribing a position to him that he never held that we can properly see how Guidobaldo understood problems that have to do with idealization in developing a mathematical science of mechanics. 
ARCHIMEDEAN ELEMENTS: REVOLVING ABOUT THE CENTRE OF GRAVITY

\section{Interpreting Archimedes Physically}

The importance of Guidobaldo's contribution to the so-called Archimedean revival of the sixteenth century is beyond doubt. His 1577 Mechanicorum liber, which was quickly translated into Italian, incorporated central Archimedean concepts, and in 1588 he published a full-blown paraphrase of and commentary on Archimedes's Equilibrium of planes. ${ }^{20}$ In this section, I will be primarily interested in Guidobaldo's understanding and analysis of Archimedes's treatise, as it is especially expressed in the latter work..$^{21}$

It is useful to start by reminding ourselves that the extant writings on mechanics of Archimedes provide all interpreters with some serious puzzles, whether these interpreters live in the twenty-first century or in the sixteenth..$^{22}$ Most conspicuous is the complete absence of any explicit definition of the notion of centre of gravity, which nevertheless is the fundamental conceptual element of the Equilibrium of planes. Guidobaldo also comments on this in his introduction to his paraphrase of Archimedes. ${ }^{23}$ Interestingly enough, his way of dealing with this absence parallels the solution of most modern commentators. He has recourse to the definition given by Pappus in the eighth book of his Mathematical collections. ${ }^{24}$ Of course, Pappus wrote centuries after Archimedes, but as Pappus himself indicates that he is following Archimedes in expounding the principles of mechanics ${ }^{25}$ Guidobaldo could feel secure in claiming that "Pappus does not depart even a nail's breadth from the principles of Archimedes". ${ }^{26}$ In a similar vein, most modern writers assume that Pappus had access to lost treatises of Archimedes (Pappus himself quotes at least one such treatise in his Collections), and that these formed the basis for his definition. ${ }^{27}$

However, prefacing Archimedes's treatise with Pappus's definition of centre of gravity is not without consequences. The definition reads as follows:

The centre of gravity of any body is a certain point within it, from which, if it is imagined to be suspended and carried, it remains stable and maintains the position which it had at the beginning, and is not set to rotation by that motion. ${ }^{28}$

This definition draws attention to a set of physical properties which are notable for their absence from the Equilibrium of planes. It is indeed surprising how devoid this treatise is of all physical interpretations of its main concepts. Nowhere does Archimedes speak about suspending weights, and even the term 'weight' (ßó $\rho \circ \varsigma$ ) is soon after the introductory postulates dropped for the more neutral 'magnitude'

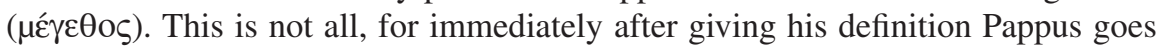
on to explain how we should understand this notion, and introduces considerations connecting weight with a tendency for motion towards the centre of the world. Again, Archimedes nowhere gives a hint of any such connection in his treatise. There are even no clear indications of the direction in which the weights or magnitudes are understood to move.

The overall tendency of Archimedes's treatise is hence characterized by a conscious 
attempt to reach as high a level of abstraction as possible. Seen from this perspective, the famous law of the lever, stated in Propositions 6 and 7, seems to be not so much about physical balancing, as about relating geometrical magnitudes to centres of gravity. And the goal of this exercise becomes clear if we consider the next propositions, which introduce properties of the centres of gravity of parallelograms and triangles. These in turn provide the means for squaring a parabola as is done in the second book of the Equilibrium of planes. (After the centre of gravity of these figures has been determined, the area of other magnitudes, such as a parabolic segment, can be determined by balancing these figures with the other magnitudes and analysing the conditions for equilibrium, exploiting the fact that the centre of gravity of the triangle is already known. ${ }^{29}$ ) The exercise in which Archimedes seems to have been engaged was not so much a mathematization of physics, but a physicalization of mathematics.

Guidobaldo at several points comments on the abstract character of Archimedes's presentation, but he always seems confident enough to offer a physical interpretation himself. He states, for example, that Archimedes chose to speak about magnitudes because this is a common name for both plane figures and solids. ${ }^{30}$ Instead of interpreting this terminology as a sign of Archimedes's desire to avoid physical connotations, Guidobaldo turns it into a means of highlighting these. Indeed, he stresses that the first eight propositions, which form the nucleus of Archimedes's treatise, are valid both for plane figures and solids (he even goes as far having the accompanying figures in his paraphrase alternately depict suspended planes and solids). ${ }^{31}$ And it is quite clear that he was rather embarrassed by the apparent restriction of the treatise to plane figures, as is testified by his convoluted discussion of the problem as to how we can understand a plane figure, which has no gravity, to have a centre of gravity. His most convincing answer seems to lie in the fact that a solid which has weight, and can be equilibrated by suspension, can be thought to have its point of suspension in its upper plane, whence we can also imagine this plane to be suspended in equilibrium as well. ${ }^{32}$ Equilibrium of plane figures is hence made dependent on equilibrium of solids. It is clear that the adoption of Pappus's definition strongly favoured — maybe even necessitated — such a view.

If Archimedes wanted his physicalization of mathematics to succeed, he somehow had to introduce physical elements into his proofs. And indeed, in the proof of the law of the lever we find him implicitly equating 'balancing' with being placed around the common centre of gravity. This is a point that Guidobaldo seizes upon to highlight the central role played by the (physical) definition of centre of gravity. In a long introductory section to the proof of Proposition 6 (the commensurable case for the law of the lever), he tries to offer an explication of Archimedes's method of proof. Now, this method crucially involves the replacement of a weight (magnitude) on a balance (line) by smaller equal weights (magnitudes), which together weigh as much (have the same magnitude) and are suspended (placed) in such a way that their centre of gravity coincides with the centre of gravity of the original weight (magnitude). It is clear that Archimedes assumes that such replacement does not alter the action of the 
weights on the balance. (Notice how hard it is not to state Archimedes's procedure in physical terms.) Which of course elicited Mach's criticism that "the entire deduction contains the proposition to be demonstrated, by assumption if not explicitly", ${ }^{33}$

Mach's criticism actually consists of two parts: firstly, Archimedes cannot prove that equilibrium is not disturbed if we replace a magnitude by another one with the same weight and centre of gravity, but of different shape; secondly, the actual form of the dependence of the action of the magnitude on its position and weight can only be the linear combination (weight $) \times($ distance $)$, given the actual replacements effected by Archimedes. The second criticism seems rather inappropriate: one can't help but wonder what's wrong with a proof that makes explicit the formal conditions underlying a procedure that is deemed valid on other grounds. The first criticism is implicitly but extensively taken up by Guidobaldo in his explication of the proof method; that is, he sets out to prove that such a replacement indeed does not disturb equilibrium, and he explicitly states that it is inadmissible to base this proof on the law of the lever. ${ }^{34}$ His proof proceeds in three steps, which I will now analyse in some detail, as they forcefully reveal how Guidobaldo dealt with the incompletely interpreted formal framework given by Archimedes's treatise by exploiting the physical nature of Pappus's definition (incompletely interpreted, because the notion of centre of gravity remains undefined, and because many other mathematical elements receive no direct physical interpretation).

\section{Guidobaldo's Physical Proof of Indifference}

The proof procedure under investigation involves the replacement of one weight, say $E$, by two smaller weights, say $B$ and $C$, which together weigh as much as $E$ and which are placed in such a way that their centre of gravity coincides with the centre of gravity of $E$ (see Figure 1). It has to be shown that both configurations are completely equivalent with respect to equilibrium with a further weight, say $A \cdot{ }^{35}$

First, Guidobaldo asks us to imagine that the weights $B$ and $C$ are suspended below

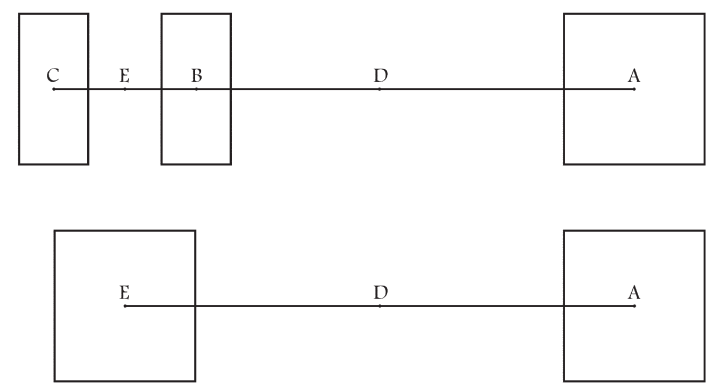

FIG. 1. Replacing the weight $E$ with two weights $B$ and $C$, which together weigh as much as $E$ and which are placed in such a way that their centre of gravity coincides with the centre of gravity of $E$, does not alter the conditions of equilibrium with a further weight A. (In duos Archimedis..., 55.) 


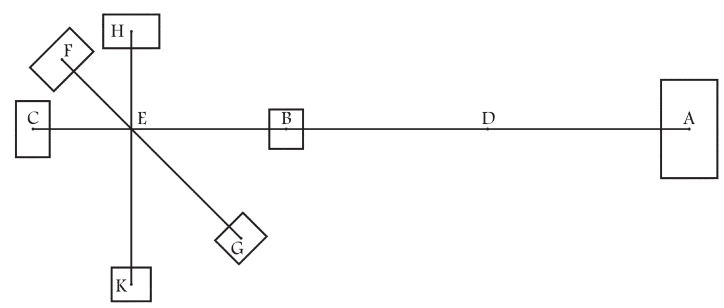

FIG. 2. Placing the weights $B$ and $C$ at places $F$ and $G$, or $K$ and $H$, such that $E$ remains their common centre of gravity does not alter the conditions of equilibrium with a further weight $A$. (In duos Archimedis..., 57.)

the line connecting $A$ and $C$. They are connected by a line which in their common centre of gravity is suspended from the line $A C$. Now, since they are suspended from their centre of gravity it follows from the definition of centre of gravity that they will be at rest. As the body composed of the two weights remains at rest, this implies that they are sustained in their centre of gravity by a power that equals their combined weight. Obviously the same power would also sustain the weight $E$ if it was suspended from its centre of gravity at the same place. Hence, both the combined weight and the single weight gravitate with their total weight in their centre of gravity. ${ }^{36}$

Next, Guidobaldo places the weights back in the line $A C$. If we now consider on this line the point $D$ which is the centre of gravity of the weights $A$ and $E$, then it obviously will also be the centre of gravity of the weights $A$ and $B$ and $C$. Hence the combined weight and the single weight are completely equivalent with respect to equilibrium with the weight $A$.

Apparently not completely satisfied, Guidobaldo moves on to a further consideration. This time he wants to compare the weights $B$ and $C$ when placed in the line $A C$ with the same weights when placed at equal distances around their centre of gravity, but at an angle to the line $A C$ (such that the new places, say $F$ and $G$, or $H$ and $K$, still lie on a straight line going through the centre of gravity, see Figure 2). Now, since the body composed of both weights when placed in $F G$ or $H K$ still has the same centre of gravity, which remains stationary, it does gravitate in the same place as it did when placed on the line $A C$. Again the same conclusion follows with respect to the body's capacities for equilibrating the weight $A$.

The crux of the whole line of argument lies in the fact that the complete weight of any body can be considered to be concentrated in its centre of gravity. And this replacement is justified through the definition of centre of gravity due to Pappus. The first and the third step merit further comments. Peculiar about the first step is the fact that Guidobaldo makes the detour through suspending the weights below the line in which they are actually placed. The reason is that he wants to argue for the equivalence of the two configurations via the equality of the sustaining power, which apparently can be most easily conceptualized if the weights are suspended from above (probably due to the fact that gravity is a natural tendency for motion downwards). This argument is actually the continuation of a line of thought which was already 
introduced earlier in Guidobaldo's paraphrase, in the preface immediately after the definition of centre of gravity and in the scholium to Proposition $4 .{ }^{37}$ That we have to sustain a body in its centre of gravity if we want completely to stop its natural motion actually refects a deeper-lying fact about the constitution of the physical world. In an Aristotelian cosmos the natural tendency for downward motion of heavy bodies is due to their striving to be at rest in the centre of the universe. Yet, the definition of centre of gravity teaches us that such a body will only be truly at rest if its centre of gravity coincides with the centre of the universe. ${ }^{38}$ But this implies that we can be more specific about this striving of a body: it is the centre of gravity that truly wants to unite itself with the centre of the universe. Which brings us back to the earlier line of argument: if we want to halt a body's natural motion, we have to arrest its centre of gravity, which is the seat of the body's gravitational action. ${ }^{39}$

Even at this place, Guidobaldo is not simply taking over pre-given scholastic metaphysical ideas, introduced to fill in the gap in Archimedes proof procedure. As he is in the first place interested in making sense of this procedure, it turns out that the actual procedure used also shapes the way we have to understand these metaphysical foundations which are hence being transformed by their incorporation within this Archimedean context. He is thus truly trying to forge a synthesis and not merely adding up distinct Aristotelian and Archimedean elements. This becomes clear in a passage in which Guidobaldo raises the worry whether two bodies merely connected by a line can be considered to be natural constituents of the physical universe. It turns out to be a sufficient answer that Archimedes considers them as such. ${ }^{40}$ If we can ascribe a centre of gravity to any combination of physical bodies, then we can consider them to be appropriately unified. This comes down to: the capacity to be held in equilibrium is what constitutes a body's unity.

We have thus gained a richer understanding of the metaphysical foundations underlying the validity of Archimedes procedure; that is, the reason why it is appropriate to consider the complete weight of any body to be concentrated in its centre of gravity. A further aspect of this procedure can be brought to light by considering the third step of Guidobaldo's overall argument. This third step crucially involves the fact that Pappus's definition of centre of gravity implies that a body suspended in its centre of gravity will always be in what we now call indifferent equilibrium (i.e. no matter what the orientation with respect to that point, the body will remain in equilibrium). It is clear that this has to be supposed for the de facto replacement of any body by its centre of gravity to make sense. If this would not be true, then the position in which a body is held would not be indifferent. To stress the relevance of this fact for an appropriate answer to Mach's criticism: if this were not the case, then the form of a body would indeed matter (as made visually clear by Figure 2, which accompanies the text).

The preceding paragraphs should suffice to show the crucial role played by Pappus's definition in interpreting Archimedes's treatise. It is seen to provide a natural link with an Aristotelian cosmological framework, exactly through the way it functions in making sense of Archimedes's proof procedures. Yet the essentially physical 
nature of Pappus's definition brings one important weakness for any theory that is built around it: it is hard to give any straightforward existence proof. That is, it is hard to see why it would be necessary at all that a point with these properties actually exists within any physical body. But we saw that Guidobaldo's interpretation of Archimedes's procedure crucially turns around the existence of a point in which a body can be held in indifferent equilibrium. As the existence of such a point can apparently only be assumed, Guidobaldo's proof seems to be left hanging in the air, suspended from a centre of gravity that might well be non-existent.

\section{ARISTOTELIAN TRACES: REVOLVING ABOUT THE FULCRUM}

\section{The Aristotelian Circle and its Centre}

The discussion of Guidobaldo's paraphrase of Archimedes's Equilibrium of planes made it abundantly clear that the latter treatise contains important lacunae from a physical point of view. We saw Guidobaldo having recourse to Pappus's definition of centre of gravity to fill in several of these, but there is another important ancient source of which we can find substantial traces in Guidobaldo's mechanics. The pseudo-Aristotelian Mechanical problems were widely disseminated and discussed throughout the sixteenth century, and it is hence not surprising that Guidobaldo paid considerable attention to them. ${ }^{41}$ In the present section, I will trace some of the general conceptual features of the treatise which found their way into Guidobaldo's mechanics. In the next section, I will take up pseudo-Aristotle's and Guidobaldo's treatment of the stability of a balance.

As with the Equilibrium of planes, any interpretation of the Mechanical problems faces considerable puzzles. In a sense these go even deeper for the latter work, as Archimedes's work was seen to be rather easily completed by the addition of a definition of centre of gravity. The Mechanical problems, rather than giving the impression of being merely incomplete, present some obscure passages, which moreover form the core of its explanatory framework. Rather than trying to unravel their precise meaning, I will be primarily interested in presenting features of Guidobaldo's mechanics that can be seen as bestowing such a meaning, although in many respects it would seem unlikely that this was the meaning intended by the Greek author. ${ }^{42}$

The central organizing principle of the Mechanical problems is the reduction of the mechanical properties of the lever (and balance) to the mathematical properties of a circle. And these latter properties are thought to be of a special nature since "the circle is made up of ... opposites, for to begin with it is composed both of the moving and of the stationary". ${ }^{43}$ A circle is generated through the motion of a line which is fixed in one point (the centre), and of which the endpoint traces the circumference. This motion moreover is of a special nature, since it is actually the result of the simultaneous performance of two movements: one natural and one unnatural. This is thought to explain "why that part of the radius of a circle which is farthest from the centre moves quicker than the smaller radius which is close to the centre, and is 
moved by the same force". ${ }^{44}$ The natural motion of the radius is somehow identified with the movement resulting from a tangentially applied force which is moving both the smaller and the greater radius, and which is thus identical for both. ${ }^{45}$ The unnatural motion is different for both, however, since it results from the influence exerted by the centre on both endpoints; and this influence is different since both points are situated at a different distance from the centre. (How to understand this 'influence' is one of the obscurities I referred to in introducing the pseudo-Aristotelian treatise; at the end of this section we will see how Guidobaldo tries to conceptualize it.) And "because the extremity of the less is nearer the fixed point than the extremity of the greater, being attracted towards the centre in the opposite direction, the extremity of the lesser radius moves more slowly" ${ }^{46}$ Having seen why a smaller radius must move more slowly, we can exploit this understanding in explaining some mechanical problems, such as "why is it that small forces can move great weights by means of a lever" ${ }^{47}$ The explanation crucially involves the identification of the relevant elements in the lever with the structural properties of a circle:

[T]here are three elements in the lever, the fulcrum, that is the cord or centre, and the two weights, the one which causes the movement, and the one that is moved.... Now the greater the distance from the fulcrum, the more easily it will move. The reason has been given before that the point further from the centre describes the greater circle.... ${ }^{48}$

A lesser weight can hence move a greater weight if it suffers less interference from the centre in making its motion. It is important to keep in mind that the Greek author does not directly identify the greater speed with the cause of the compensation for the lesser weight, but starts from a deeper-lying explanation of this greater speed.

It was noted in the previous section that Guidobaldo at several points provided Archimedes's abstract treatise with appropriate physical interpretations. One of the missing physical elements in this treatise is a fulcrum as the fixed point around which a lever and balance can turn. In his scholium to the first Archimedean postulate Guidobaldo immediately posits such a point and goes on to identify it directly with the Aristotelian 'centre': "that point, moreover, that Archimedes admits, and from where the distances from which the weights are hung are measured, ... Aristotle calls centre." ${ }^{49}$ That this was by no means a gratuitous identification for Guidobaldo is testified by his Mechanicorum liber. There we find him having recourse to the general Aristotelian explanatory structure, including the crucial role of the centre, when he engages in a polemic with Tartaglia and other proponents of Jordanus's views on positional gravity (this polemic will be further analysed in the next section).

\section{The Causal Role of the Fulcrum}

Jordanus, and following him Tartaglia, had posited that a body that is constrained by a rigid bar to move on a circle will move more swiftly as its position is closer to the horizontal diameter, and Guidobaldo reproaches them for having failed to uncover the true cause of this fact. This is shown by him to consist in the different influence 
the stationary centre of the moving bar exerts on the weight according to the latter's position. Imagine the weight as it rests on the bar while this stands perpendicular on the horizon: as it weighs down on the bar, and hence on the centre which cannot move, the bar will have to resist the body's tendency for downward motion and push back against it. The result is that the body will be deprived completely of its tendency to descend. Now imagine the weight attached to the bar which is held in a position somewhere in between the horizontal and the perpendicular: it will still weigh down on the bar, but the resistance offered by the bar will not be complete, as the direction of the body's tendency for motion and the direction in which the bar can push back against the body no longer coincide. Finally, when we imagine the weight attached to the bar as the latter is perpendicular to the direction of the body's tendency to motion, the body will retain its complete tendency for motion.

It is striking how closely Guidobaldo in his explanation approaches a modern understanding of the effects of constraints on the motion of bodies, when we identify the push back of the arm with a constraining force in the sense of classical mechanics and the resulting tangential force with the tendency for motion of the partly sustained weight. (Such assimilation would of course require a sophisticated understanding of the composition of forces which we cannot easily ascribe to Guidobaldo.$^{50}$ ) At the same time, it is striking how close Guidobaldo stays to the Aristotelian explanatory framework, where the resulting speed of motion is also identified with the resultant of the combination of the natural motion of a body and the influence exerted by the stationary centre. Such assimilation becomes even more striking when we find Guidobaldo extending his explanation to the effect of the length of the rigid arm on the swiftness of the motion. Yet this extension at the same time shows the limits of this assimilation. Guidobaldo has crucially transformed the Aristotelian explanation by adding a different (almost 'modern', we could be tempted to say) understanding of the interaction between weight and centre, based on an action-reaction pair. While this opens up a potentially forceful and coherent understanding of the variations of the dynamic effects of a constrained weight, it is incapable of explaining the effect of the length of a lever arm, which was the prime objective of the Aristotelian explanation. If Guidobaldo wants to explain the latter case without straightforwardly reverting (which he nevertheless might give the impression of doing) to the Jordanian idea that it is the straightness of the virtual motion that explains the difference in apparent weight — an idea which he had earlier criticized as not truly demonstrative — then he can effect this only by an implicit reversal to the vague Aristotelian 'influence' of the centre on the weight. It is thus the general Aristotelian explanatory structure of the stationary centre constraining/influencing the moving weight that keeps together Guidobaldo's own attempts at causal analysis.

By introducing the Aristotelian 'centre' as a fulcrum in Archimedes's treatise, Guidobaldo also incorporates the explanatory structure going with it. Accordingly he provides the abstract treatise with a further physical and causal interpretation. It is hence not surprising that he goes as far as claiming that Archimedes most probably took some of his postulates from the Aristotelian treatise. ${ }^{51}$ Given the fact 
that Guidobaldo had also seized upon Pappus's definition of centre of gravity as a genuine Archimedean element, this need not be "a curious theory of the history of mechanics", ${ }^{52}$ as both this definition and the Aristotelian explanatory structure make a lot out of the physical suspension of bodies in a central point. It is moreover precisely the duality of both centres, the centre of gravity and the fulcrum, that provides Guidobaldo with his most powerful explanatory strategy in his Mechanicorum liber (as will be seen in the next section). The same can be said about Archimedes's Equilibrium of planes, which first assumes that a body will prevail over another one if it is farther from the 'centre' than the other one, and then goes on to show what is the general condition for equilibrium by demanding that the 'centre' coincides with the centre of gravity of both bodies taken together. Finally, Guidobaldo could have found convincing historical confirmation for his claim in Pappus's reference to a lost treatise of Archimedes in which is ascribed to Archimedes exactly the proposition that greater circles overcome smaller ones. ${ }^{53}$

SYNTHESIS: REVOLVING ABOUT THE CENTRE OF THE WORLD

\section{The Stability of the Balance: Arguing Against Positional Gravity}

Up to now we have encountered two different respects in which Guidobaldo incorporated the Archimedean Equilibrium of planes within a broader Aristotelian framework. On the one hand, the physical definition of centre of gravity allowed him to integrate the Archimedean treatment of equilibrium within the general cosmological constitution of the universe. On the other hand, the Aristotelian treatment of the cause of disequilibrium allowed him to supply part of the missing physical structure in the Archimedean treatise. In a convoluted discussion in his Mechanicorum liber we can find both strands coming together.

The Mechanicorum liber opens with Pappus's definition of centre of gravity, accompanied by the corresponding definition due to Commandino, followed by a few obvious axioms about weight as a magnitude, and three suppositions, which read as follows: ${ }^{54}$

1. Every body has but a single centre of gravity.

2. The centre of gravity of any body is always in the same place with respect to that body.

3. A heavy body descends according to its centre of gravity.

The first section of the treatise concerns the stability of the balance. The first propositions introduce propositions concerning the stability of an equal arm balance with equal weights as it is sustained respectively above, under, and in its centre of gravity. All proofs combine a straightforward application of the Archimedean determination of the centre of gravity with the supposition that a body descends according to its centre of gravity (and the implicit acknowledgement that the fulcrum is a fixed point which must remain stationary). If the balance is sustained from above and removed from the horizontal position, the centre of gravity will be raised, and hence if the 


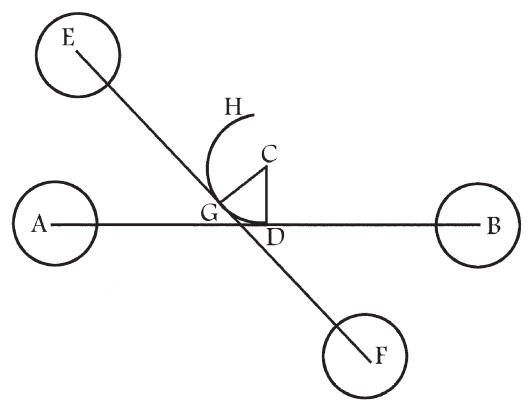

FIG. 3. When a balance is sustained in a point $C$ above its centre of gravity it will be in stable equilibrium: if it is moved from position $A B$ to the position $E F$, its centre of gravity will be raised from the position $D$ to the position $G$; its centre of gravity will naturally descend back to the position $D$ which is situated lower down; hence we have stable equilibrium. (Mechanicorum liber, 4r.)

balance is released the centre will be able to descend until the balance is again in horizontal position (see Figure 3). The two other cases can be treated in a completely similar way (the centre of gravity will be respectively lowered - and will be able to keep on descending - and remain stationary). Hence we have respectively stable, unstable and indifferent equilibrium.

Immediately after the proof of indifferent equilibrium, Guidobaldo enters into a sustained polemical discussion of Jordanus and other writers who want to base mechanics on the notion of positional gravity. This discussion has given rise to misapprehensions concerning Guidobaldo's own views, as it can be very misleading to consider only parts of this polemic without keeping an eye on the overall argument. In what follows, I will accordingly first try to summarize the different steps in Guidobaldo's argument, paying special attention to the often criticized focus on what we might term the 'non-parallelness' of the lines of descend of weights suspended on a balance.

The occasion that triggers the discussion is the existence of indifferent equilibrium, which was denied by Jordanus, Tartaglia and others (although they did not use that name for the state they assumed to be impossible). ${ }^{55}$ According to these authors, a balance would never be in indifferent equilibrium since the weight on a depressed arm is always 'positionally lighter' (as they called it) than the weight on the other arm. Hence a balance with equal weights, suspended in its centre, always returns to a horizontal position.

In a first step, Guidobaldo reiterates his proof of Proposition 4, which states the case of indifferent equilibrium, but with a slightly different emphasis. Instead of giving a direct proof, he reduces the claim that an equal arm balance sustained in its centre would have stable equilibrium to absurdity, by showing that this would imply that the centre of gravity of a given body would not be unique, contrary to the first postulate.

Next, Guidobaldo identifies a mathematical error in Tartaglia's and Jordanus's argument concerning the supposedly smallest ratio of angles. This argument was 
explicitly designed to save a theory based on the notion of positional gravity from some strange consequences, but it could also be used to undercut Guidobaldo's argument. Its main point consists in showing that, although the weight on the elevated arm is positionally heavier than the weight on the depressed arm, the difference in heaviness is always infinitesimally small and hence cannot be offset by adding a small weight to the positionally lighter weight. The relevance of this argument for Guidobaldo's argumentation lies in the fact that this could be used to argue that although the one weight would be positionally heavier than the other, the centre of gravity of both weights would not change and hence still be unique. The resulting theory would of course have a strange notion of centre of gravity, but Guidobaldo is clearly determined not to leave any room for his adversaries.

Not only is the argument concerning the ratio of angles wrong on its own terms, it also assumes that the lines of descent of the weights at both ends of the balance are parallel, contrary to what Tartaglia states at other places. Guidobaldo thus introduces the convergence of the lines of descent towards the centre of the world into the argument to tackle Tartaglia on his own ground. He immediately deduces that as a consequence of this convergence the weight on the depressed arm should always be positionally heavier, and that hence even stable equilibrium is inconsistent with the theory of positional gravity (see Figure 4).

As a next step, Guidobaldo summarizes the arguments on which grounds the

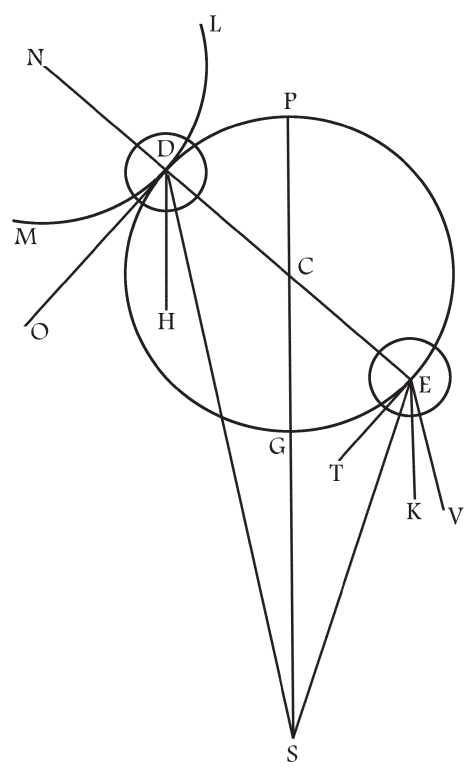

FIG. 4. Since the lines of descent of the bodies at $D$ and $E$ converge in $S$, the centre of the world, the body at the lower position $E$ will always have to be positionally heavier, according to the views of Tartaglia and Jordanus, because the angle SEG is less than SDG. It follows that even stable equilibrium would be impossible on these authors' own assumptions. (Mechanicorum liber, 8r.) 
theory of positional heaviness would destroy the possibility of indifferent equilibrium. Firstly, it is assumed that the closer a weight is to the horizontal position, the heavier it will be. This in turn is due to the fact that it will be moving more swiftly because it is farther from the perpendicular erected on the centre of the balance. Secondly, this difference in positional gravity can also be deduced from the different degrees of straightness of the arcs at different places along the circle described by the balance arm. ${ }^{56}$

Guidobaldo agrees that a weight will move swifter if it is closer to the horizontal position, but he also claims that the theory of positional gravity fails to deliver the true reason for this fact. This is proved by showing that the true cause involves an explanation wholly absent in the writings of Tartaglia and Jordanus. This explanation is the one that was summarized in the previous section. It is followed by a long passage in which this explanation is applied to different configurations of the position of the centre of the weight's arm of suspension with respect to the centre of the world. The conclusion is that the position where a body would have the greatest 'free' weight changes with this relative position (as the position where the line of descent and the arm of the balance are perpendicular changes, see Figure 5). This digression does not directly touch on the arguments concerning positional weight; at this point

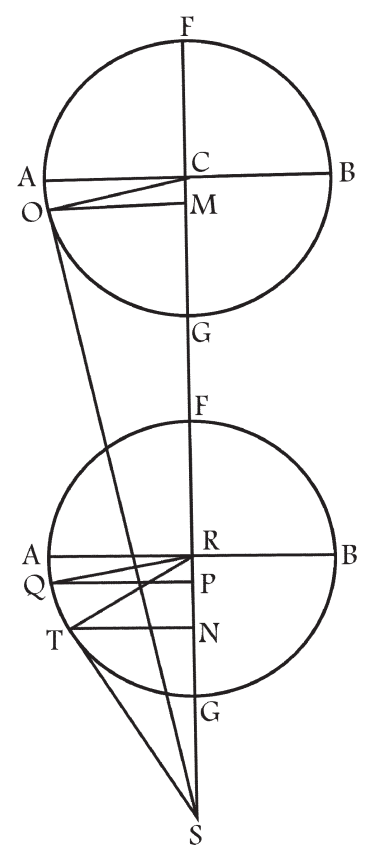

FIG. 5. The position where a body would have the greatest 'free' weight changes with the relative position of the balance with respect to the centre of the world $S$ as the position where the line of descent and the arm of the balance are perpendicular changes (in this example from position $O$ in the upper balance to position $T$ in the lower one). (Mechanicorum liber, 12v.) 
Guidobaldo seems rather to be assessing the possible effect of the convergence of the lines of descent on his own theory.

The explanation grounded in the different curvatures of the arc is first attacked by showing again that it is incompatible with the convergence of the lines of descent. However, this time Guidobaldo seems to agree that this might be taken as mere hairsplitting since this convergence must remain imperceptible. Thus, he goes on to offer a further foundational critique of the notion of positional gravity. Firstly, he argues that the notion is incoherent, since a weight might be assigned different positional gravities depending on the way one considers its position. This is due to the fact that the curvature of an arc depends on the length of the segment one considers. ${ }^{57}$ Secondly, the theory contains a crucial ambiguity which renders it unable correctly to assess the stability of a balance. The arguments concerning the impossibility of indifferent equilibrium were all based on a misapprehension of the way the two weights on the ends of the balance should be considered. The potential descent of the one was compared with the potential descent of the other, whereas it should have been compared with the latter's potential ascent since the two weights are always moving on the opposite arms of a balance.

\section{Parallel Lines of Descent}

At this point we are over halfway through the extended discussion appended after the fourth proposition. In the part that follows, Guidobaldo leaves behind the straightforward criticism of the notion of positional gravity, and further expands on the proper way to understand the stability of a balance. This involves two crucial explanatory features, which I will take up in turn as it is here that we can best assess the kernel of Guidobaldo's understanding of the right way to conceptualize mechanical problems.

Firstly, and most conspicuously given the criticisms that were levelled by Duhem and others at precisely this point, Guidobaldo reintroduces parallelness for the lines of descent of the weights suspended on the opposing arms of a balance. Immediately after criticizing Jordanus and Tartaglia for having neglected the effect of the conjunction of weights moving on the opposite arms of a balance in assessing stability, Guidobaldo claims that as a further effect of this conjunction the lines of descent will become parallel.

Secondly, Guidobaldo stresses that the different types of stability are governed by the duality between centre of suspension and centre of gravity. He further points out the structural similarity between his explanation and the one offered by (pseudo-) Aristotle in the Mechanical problems. The latter of course did not involve the notion of centre of gravity, but this notion can now be imputed to the Aristotelian author because of this structural similarity. Yet, as Guidobaldo himself notices, "Aristotle poses only two questions [stable and unstable equilibrium] and leaves out the third; that is, the case in which the centre of the balance is in the balance itself". ${ }^{58}$ Hence, it is exactly the most crucial case that is missing in the Greek treatise. Guidobaldo is not disturbed by this: "But he left this out as a thing well known, as he usually did 
omit obvious things. Who can doubt that, if the weight is sustained at its centre of gravity, it will remain at rest?" 59 No one, of course; that is, no one who accepts the existence of the centre of gravity as defined by Pappus....

The structural similarity between Guidobaldo's and Aristotle's treatment can be secured only via a not-very-subtle rhetorical strategy. Yet, as was argued in the previous section, it is no accident that the duality between the two centres is stressed through a reference to the Mechanical problems. What is interesting is not so much that Guidobaldo unconvincingly attributes a knowledge of barycentric theory to Aristotle, but that he takes over an Aristotelian focus on the physical effects of the stationary character of the point around which the weights move, and integrates this within a barycentric theory. If the fulcrum is for example situated above the centre of gravity, then the geometry of the situation immediately shows that the weight on the raised arm of a balance will be more 'free' — i.e. less sustained — than the opposite weight, and the balance will have to return to a horizontal position (see Figure 6). Guidobaldo's explanations at this point can be purely geometrical since he has already analysed the physics accompanying this geometry. However, as was already indicated, an essential part of this geometry is the fact that the lines of descent of both weights are taken to be parallel. How can this be squared with Guidobaldo's recurrent critique of other authors' neglect of the actual convergence of these lines?

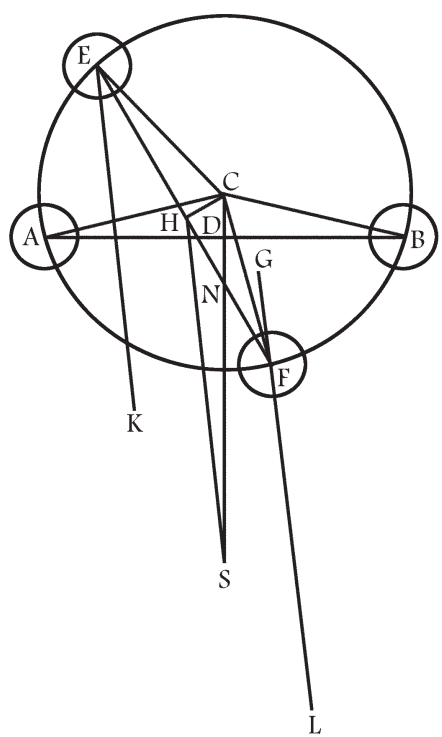

FIG. 6. If the fulcrum $C$ is situated above the centre of gravity $H$ of the balance, the geometry of the situation immediately shows that the weight $E$ on the raised arm of a balance will be more 'free' - i.e. less sustained - than the opposite weight $F$, because the angle $K E C$ is larger than $F G C$, and the balance will have to return to a horizontal position. (Mechanicorum liber, 23r.) 
The reason why Guidobaldo returns to parallel lines of descent is clearly indicated by himself: if he did not do this, he would be confronted with the same problem as he had uncovered for the proponents of positional gravity. After all, his own analysis of the differences in 'free' weight due to the relative direction of the line of descent of a weight with respect to the arm from which it is suspended, gives the same results as the analyses based on the notion of positional gravity. But he had already shown that from the combination of the latter with the fact that the lines of descent converge in the centre of the world there follows the undesired result that the weight on the raised arm of a balance would have to be positionally lighter than the weight on the depressed arm. All that Guidobaldo offers by way of a direct justification for returning to parallel lines is the following:

But if the weights $E$ and $D$ are joined together and we consider them with respect to their conjunction, the natural inclination of the weight placed at $E$ will be along the line $M E K$, because the weighing down of the other weight at $D$ has the effect that the weight placed at $E$ must weigh down not along the line $E S$, but along $E K .^{60}$

The line $E S$ is the line connecting the weight $E$ with the centre of the world $S$, whereas the line $E K$ is a line through $E$ but parallel with the line connecting the centre of gravity of $E$ and $D$ with the centre of world (see Figure 7).

There is no further explanation of how this weighing down is to be understood, which is especially problematic given the fact that Guidobaldo's earlier analysis crucially rested on the fact that the weight at $D$ already weighs down on the fulcrum which remains stationary. It might thus seem that Guidobaldo's justification must remain completely ad hoc. There is however one further feature about it which merits closer attention, and which will bring forth a greater coherence in Guidobaldo's conceptualization of this problem than might be apparent at first sight - and one that is certainly greater than acknowledged by Duhem et alteri.

The lines of descent are not just posited to be parallel to each other, but also to be parallel to the line connecting their centre of gravity with the centre of the world. This is immediately relevant, because if Guidobaldo has a means to justify this, he also has resources which are unavailable to the proponents of a theory based on the notion of positional gravity. He could hence at the same time criticize them for neglecting the convergence of the lines of descent and hold on to parallel lines in his own conceptualization. And if we remember Guidobaldo's understanding of the notion of centre of gravity as it was evinced in his comments on On the equilibrium of planes, it becomes clear that he is not just positing an arbitrary stipulation.

One of the main features of the centre of gravity was that it is connected in a crucial way with the cosmological structure of an Aristotelian cosmos. We saw that it is the centre of gravity which truly wants to unite itself with the centre of the universe (a fact which is also expressed in the third supposition of the Mechanicorum liber, quoted above). The present argument for the parallelness of the lines of descent can be understood as a straightforward extension of this understanding. 


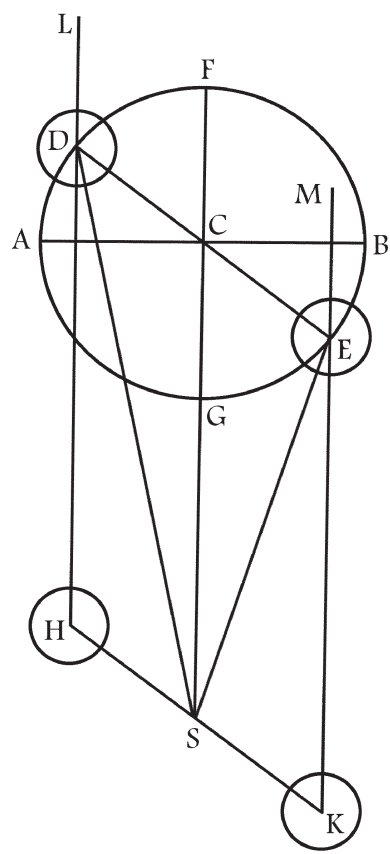

FIG. 7. A balance with weights $D$ and $E$ is supported at its centre of gravity $C$. The point $S$ represents the centre of the world. The lines of independent descent are $D S$ and $E S$, but since the line of descent of the centre of gravity is $C S$ the weights are actually constrained to descend along the lines $D H$ and $E K$, hence restoring parallelism for the lines of descent. (Mechanicorum liber, 19v.)

The figure accompanying the text at this point clarifies this further (see Figure 7). A balance in a raised position is shown, as are the lines of independent descent of the two weights and the line of descent of their centre of gravity, all converging in the centre of the world. The balance is also shown with its centre of gravity in the centre of the world, its arms parallel to the original position. If we now draw lines from the weights in their original position to the same weights in this latter position, we have their paths of descent as their centre of gravity descends towards the centre of the world: lines which are parallel with each other, and with the line of descent of the centre of gravity. ${ }^{61}$

\section{The Three Centres}

Drawing all the themes of this discussion together, we can see that Guidobaldo's understanding of the stability of balances is structured by a three-fold organization. The duality between centre of gravity and fulcrum can only play its explanatory role because there also exists an intimate relationship between the centre of gravity and the centre of the world, which gives a balance its required unity so that the lines of descent of the suspended weights have to be considered parallel. In a comment that 
was introduced by Pigafetta in the Italian translation of the Liber mechanicorum, but which was actually due to Guidobaldo, ${ }^{62}$ we find him stressing this three-fold structure himself:

Now our author is the first to have considered the balance in detail and to have understood its nature and its true quality. For he is the first of all to have shown clearly the way of dealing with it and teaching about it, by propounding three centres to be considered in its theory: one is the centre of the world, another the centre of the balance, and finally the centre of gravity of the balance: for in this was a hidden secret of nature. Without these three centres, it is clear that one could not come to a perfect knowledge or demonstrate the various properties of the balance.... ${ }^{63}$

Guidobaldo's conceptualization of mechanical phenomena essentially involves both what he had found in Aristotle and his followers, and what he had learned from Archimedes. Its basic conceptual element, centre of gravity, is of Archimedean origin, but the way it functions is co-determined by an Aristotelian cosmological frame and by the particular Aristotelian understanding of the balance.

There is one further strand running through Guidobaldo's discussion that remains to be taken up. It was already remarked upon that Pappus's definition of centre of gravity is of an essentially physical nature, and that therefore the notion can be given no straightforward existence proof. At the same time, we saw Guidobaldo axiomatically holding on to its unique existence in his first criticisms directed against Jordanus and Tartaglia (that the difference in positional gravity of weights on opposite arms would imply the non-uniqueness of the centre of gravity of a balance), on the basis of his first two suppositions, quoted above. This straightforward connection between the possibility of indifferent equilibrium and the existence and uniqueness of the centre of gravity brings to light what is really at stake for Guidobaldo in his polemic with the proponents of the notion of positional gravity. By denying indifferent stability, they take away the well-foundedness of the whole concept of centre of gravity (hence also Guidobaldo's confidence in claiming that Archimedes seems to have been of the same opinion as him concerning the stability of balances, a topic never mentioned by Archimedes). ${ }^{64}$

If we take a look at the discussion from this perspective, a further significant link with the issue of the parallel lines of descent comes to the fore. Precisely because the convergence of the lines of descent would imply the impossibility of indifferent equilibrium, it would also threaten Guidobaldo's mechanics in its true core. This connection would again become a central issue in the mainly French discussion concerning Jean de Beaugrand's Geostatice in the 1630s. ${ }^{65}$ It could hardly have escaped Guidobaldo's attention, given his extended discussion of the effects of the relative position of a weight with respect to the centre of the world on its 'free' weight when suspended from a balance arm, which would directly imply that the common centre of gravity of weights on the opposite arms of a single balance would change with the inclination of the balance. ${ }^{66}$ Yet, it is crucial to Guidobaldo's mechanics that this 
insight cannot be applied to connected weights, because he holds on axiomatically to the unique existence of a body's centre of gravity. And precisely because he holds on to its existence, he has the resources to argue for the parallelness of the lines of descent.

All this might give the impression that we are trapped in a kind of circularity, which only highlights the coherence of Guidobaldo's position, but has nothing to say about its well-foundedness. There are two reasons why this is not completely true. Firstly, if there is no way to restore the parallelness of the lines of descent, even stable equilibrium will not be possible. Hence, even if one does not necessarily want to hold on to indifferent equilibrium, there is still a good reason why one would want to be able to argue that the lines should be parallel. But the notion of positional gravity provides no clue whatsoever on this score, whereas the notion of centre of gravity does. Of course, one could decide to ignore the convergence of the lines of descent because it must remain imperceptible. Yet, secondly, Guidobaldo has another argument why his mechanics is truly well-founded. He claims to have been able to construct an empirical balance that shows indifferent equilibrium. ${ }^{67}$ In the end, it is thus an empirical proof that secures the existence of the centre of gravity as defined by Pappus, and hence also shows that Archimedes's proof procedure in his Equilibrium of planes is completely legitimate. But the attention for the different types of stability was due to the Aristotelian Mechanical problems, which accordingly points the way to the necessary empirical foundations for the abstract Archimedean treatise. ${ }^{68}$

\section{OF WEIGHT AND POWER}

\section{The Mechanical Machines}

In the previous sections we have seen the intricate ways in which Guidobaldo's conceptual structuring of the science of mechanics revolves around the three centres, and consequently has a truly Aristotelian-Archimedean character. In the section that follows, a preliminary attempt will be made to reconnect this analysis with some of the issues surrounding Guidobaldo's broadly conceived 'scientific project'. But before coming to these concluding remarks, it is important to assess some consequences of this way of conceptualizing mechanical phenomena; consequences that can be judged from the other sections in the Mechanicorum liber that follow upon the treatment of the balance.

Guidobaldo follows Pappus in reducing the other mechanical instruments to a combination of levers. In a letter to Pigafetta, he moreover states that the lever and the balance operate on exactly the same principles, the only difference being the mode of operating: a balance has weights on both ends whereas to a lever is applied another kind of power at one end. ${ }^{69}$ But if we have a look at his way of determining the exact proportions governing the use of a lever, we immediately find him assimilating these applied powers to suspended weights, hence effectively transforming a lever into a balance. ${ }^{70}$ This allows Guidobaldo to apply the conceptual structure that 
we discerned in the foregoing sections to the lever: first he demands that the fulcrum should coincide with the common centre of gravity of the weight to be sustained and a weight suspended at the point of application of the force; and only afterwards does he set the force to be applied equal to the weight that is thus determined.

The most important innovation introduced in the section on the lever is that the fulcrum must no longer of necessity lie in between the weight and the applied power/ assimilated weight. This will of course be of capital importance in reducing a system of pulleys to a system of levers. Guidobaldo adduces two equivalent ways of proving the exact proportions holding between sustaining power and suspended weight for such levers with suspended weight in between the fulcrum and the applied power; both crucially replace powers by suspended weight and then exploit the rational principles that hold for weights on a balance. His second method straightforwardly reverts to the balance model by imagining the lever arm to be extended at the other side of the fulcrum where a weight equal to the weight to be sustained is suspended at an equal distance from the fulcrum; a weight which in its turn can be held in equilibrium by a smaller weight suspended from the point at which the power must be applied. His first method is more interesting since it comes close to introducing something akin to the notion of static moment. ${ }^{71}$ It exploits the idea that bodies of the same weight (pondus) can have different gravity (gravitas) depending on their relative position to the fulcrum, by setting the power equal to the pondus of a suspended weight that has as much gravitas as the weight to be sustained by that power. Yet the way he determines this gravitas is again through a straightforward identification of the position of the centre of gravity with the position of the fulcrum.

\section{The Effect of the Direction of Applied Power}

Guidobaldo had no way of understanding the effect of a power other than by assimilating it to a weight having a natural tendency downward which could be introduced in arguments involving centres of gravity. In a corollary to the third proposition on the lever he even claims that all the proportions established remain valid if the lever is not held in a horizontal position, since this follows from what was said about the balance ${ }^{72}$ - obviously referring to the discussions on indifferent equilibrium. Immediately afterwards he corrects this statement, yet not as we would expect by introducing the effect of the different directions in which a power can be applied, but by analysing the effects of different ways in which the weight to be sustained can be attached to the lever. His lack of attention to the effect of the direction of the applied power can be partly explained by noticing that it plays no role when we are dealing with pulleys, where the powers are always applied vertically. ${ }^{73}$ And it is clear, through the sheer weight of exhaustive discussions of different kinds of arrangements, that the section on the pulley forms the main goal of the treatise. As the lever seems to be primarily introduced to explain the workings of pulleys, explicit discussions of the direction of the applied power are not that important. However, contrary to what Duhem claims, ${ }^{74}$ Guidobaldo did realize that this could have significant effects.

In a passage on the wheel and axle (see Figure 8), Guidobaldo discusses the effect 


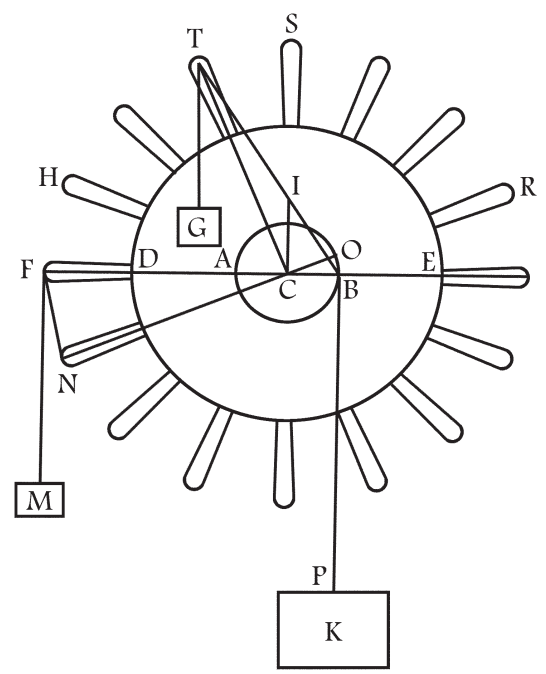

FIG. 8. A power is applied to the wheel and axle at handle $T$, which is situated higher than the common axis of wheel and axle. The weight $G$ will balance the weight suspended from the axle when their common centre of gravity $I$, lying on the line $T B$ connecting both points of suspension, is situated perpendicularily above the common centre $C$ of both wheel and axle, which functions as a fulcrum. An elementary geometrical calculation shows that this centre of gravity lies closer to the weight when this is suspended from a position that is higher on the wheel; whence a weight must be heavier to sustain the other weight from this position. (Mechanicorum liber, p. 108r.)

of applying the power at different places at the wheel. He notices that if we apply the power to handle $T$, which is situated higher than the common axis of wheel and axle, then we get different results for the necessary sustaining power, depending on whether we "were to apply a living force to sustain the weight ..., acting as if it wished to reach the centre of the world, as did the weight applied [there] by its own nature" or if "the handle were pressed by the hand". ${ }^{75}$ Guidobaldo again introduces considerations on the relative positions of fulcrum and centre of gravity to justify this difference. The weight $G$ will balance the weight suspended from the axle when their common centre of gravity, lying on the line $T B$ connecting both points of suspension, is situated perpendicularly above the common centre $C$ of both wheel and axle, which functions as a fulcrum. An elementary geometrical calculation shows that this centre of gravity lies closer to the weight when this is suspended from a position that is higher on the wheel; whence a weight must be heavier to sustain the other weight from this position. This special case of what we would call a bent lever is hence reduced to a balance which is sustained in a point under its centre of gravity. ${ }^{76}$ This is a procedure that could be generalized to give a treatment of all kinds of bent levers, as long as the power applied can be assimilated to a suspended weight. The latter limitation is of course highly important: if the lines of force are no longer parallel, the notion of centre of gravity loses all sense for Guidobaldo, 
and his explanatory scheme breaks down.

Guidobaldo nevertheless also claims that when the power is applied perpendicularly (as when pressed by a hand) the position on the wheel makes no difference. This seems to betray a more general analysis of the effect of directionality of forces, and hence would be a reason to attribute an understanding of what we call static moment to Guidobaldo. This attribution could be further strengthened by considering the argument that he actually gives for this indifference. He claims that this follows from the fact that powers applied perpendicularly at both the points $T$ and $F$ have their inclination along the circumference at the same distance from the centre. ${ }^{77}$ This seems to imply that he considers the relevant factor responsible for sustaining the suspended weight to be the component of the force working along the line of motion of the lever, combined with the distance from the fulcrum. If we further connect this with his analysis of the effect of constraint on the force of weight, then a general conception of static moment seems to be completely within Guidobaldo's reach. However, it must be remembered that he wrongly suggested that his analysis of constraint would also explain the effect of the length of the lever arm, which clearly undercuts any arguments that would ascribe to Guidobaldo an understanding of what we call static moment. And most importantly, we cannot ignore the fact that he simply did not take this step - he clearly preferred to ground his analysis as much as possible in the concept of centre of gravity. Nowhere else in his writings are there any discussions of the effects of the directions of applied forces. ${ }^{78}$

Guidobaldo's insight in the differences between powers applied perpendicularly and weights suspended vertically is more nuanced than the simple ignorance ascribed to him by Duhem. Contrary to Henninger-Voss's claim that "Guidobaldo seems to have analysed all machines from the unstated assumption that they always move according to the manner in which they are employed by workers" ${ }^{79}$ which was based exactly on Duhem's mistaken argument, we must stress that Guidobaldo analysed almost all machines from the stated assumption that they are operated as if they were moved by suspended weights. Guidobaldo's mechanics is essentially a science of weights, which always have their natural inclinations, but which can be put to human use through a clever exploitation of the properties of centres of gravity. And this exploitation finds place both at the level of the organization of rational principles, as we saw in his polemic against Tartaglia and Jordanus, as at the level of bringing these principles into operative act. ${ }^{80}$

\section{THE DYNAMICS OF STABILITY}

\section{Guildobaldo's Mixed Science}

The concept of centre of gravity provides Guidobaldo's mechanics with the necessary conceptual stability. Through its multiple guises, it can play different roles simultaneously. It is both an essentially physical notion, which at the same time connects mechanics with a general cosmological structure and can be found incarnated in 
all particular mechanical machines, and a mathematical notion, which allows the construction of a deductive theory on its basis. ${ }^{81}$ In this concluding section, I will try to bring out some aspects of the part that is played by these roles in shaping Guidobaldo's scientific project.

There is an oft-repeated judgement that Guidobaldo denounced the ideas of Jordanus out of a misplaced homage to ancient authors (and a consequent rejection of medieval writers), and because he held on to an idea of absolute mathematical rigour. ${ }^{82}$ The latter is especially thought to be illustrated by his insistence on the convergence of the lines of descent. However, we have seen that Guidobaldo insists on this convergence only in a specific context, namely in his polemic against Tartaglia and Jordanus. The belief in the reality of this convergence was something he shared with his opponents; but whereas it destroyed the coherence of their arguments, he could evade its undesired consequences. It is thus put to a very specific argumentative use, and nowhere does Guidobaldo suggest that all mechanical explanations should take account of this fact — quite the contrary. In an almost paradoxical way Guidobaldo introduces this convergence into the discussion to preserve the possibility of indifferent equilibrium (whereas on first sight this fact would seem to destroy this possibility). It is this possibility that is truly at stake, and with it the well-foundedness of the notion of centre of gravity. Because these authors had argued against indifferent equilibrium, they could in no way possess true science. This is what the long polemic discussion is designed to show. ${ }^{83}$ In the same vein it is not so much the notion of positional gravity as such that is criticized (after all, Guidobaldo's analysis of the effect of constrainment on the 'freedom' of a weight was explicitly designed to give the same results), but its organizing power - without the concept of centre of gravity, one is bound to run into insurmountable troubles.

The empirical proof of indifferent equilibrium was seen to occupy a crucial place in securing the foundations of Guiodbaldo's mechanics. At several places Guidobaldo stresses that it is essential to him that such empirical foundations be provided ${ }^{84}$ This focus on the empirical underpinning of the principles of his science allows us to see Guidobaldo's mechanics as an exemplary instantiation of the Aristotelian category of the mixed sciences. ${ }^{85}$ In establishing a mixed science one has to be able to show that a set of physical objects have some characteristics in virtue of which they are amenable to a mathematical treatment; this treatment then involves giving mathematical explanations of why a host of (mathematical) properties hold of these objects. It is evidently possible to give a mathematical description of a balance (based on the magnitudes of weight and length), and Aristotle and Archimedes have moreover shown how to exploit this mathematical description to explain different properties that hold of a balance qua mathematical instrument. This is possible because we can start from some communes notiones and suppositiones that characterize the mathematical concepts of weight and centre of gravity as holding of any physical balance. ${ }^{86}$ On the basis of these properties we can then exploit mathematical reasoning to demonstrate a host of remarkable properties (such as the different kinds of stability, or the precise ratios for the multiplication of force in a system of pulleys). The foregoing discussions 
have shown how the balance incarnates the essential conceptual features of mechanics in its different kinds of stability, features that only have to be expressed symbolically and ordered methodically by the mathematician. (This also helps understanding how Guidobaldo could have ascribed barycentric theory to Aristotle on account of no more than his treatment of the stability of balances.)

Apparently in opposition to Guidobaldo's stress on the need for empirical underpinnings, Tartaglia had claimed that mechanical phenomena could be considered either "in abstraction from all matter", or through material tests and physical arguments, but that we should not confuse these two modes of consideration. ${ }^{87}$ But as Guildobaldo retorts, this actually implies that it becomes completely mysterious why this would still be a mathematical science of mechanics; as he famously expresses it: "mechanics can no longer be called mechanics when it is abstracted and separated from machines." 88 To borrow Henninger-Voss's assessment: Tartaglia's science seems to be rather a mixed-up than a mixed mathematical science. ${ }^{89}$

\section{Idealization in Guidobaldo's Science}

Tartaglia had made his claim in a very precise context, however, i.e. when commenting on the difficulties that everyone is bound to notice when trying to verify theoretically established properties in empirical situations. He concludes that the presence of matter would necessarily hinder the truth of propositions proved mathematically in the abstract. Guidobaldo is of course aware of this problem, as he warns us (through the intermediary voice of Pigafetta) that:

... in performing this experiment one might not act hastily, for it is an extremely difficult thing ... to make a balance which is sustained precisely at the centre of its arms and at its precise centre of gravity. For this reason it is good to remember that, when anyone tries to perform such an experiment and does not succeed, he should not be discouraged, but rather should say that he had not been careful enough, and should try repeatedly until the balance is just and equal and is sustained precisely at its centre of gravity. ${ }^{90}$

The symbolic expression and methodological ordering cannot be attained through a straightforward inductive process. It is rather because Guidobaldo already has the proper rational principles that he is able to teach where we can find their incarnation. The important difference with Tartaglia's pessimistic attitude is hence that Guidobaldo is confident that, given the right set of principles, these can always be found to be empirically exemplified.

It is here that we can also find the background to Guidobaldo's claim that a moving force is always greater than a sustaining force, which implies the impossibility of extending the precise proportions established for equilibrium to situations in which the weights are moving. ${ }^{91}$ It may be hard to determine precisely the centre of gravity of a physical balance, but whenever it is suspended in it, it will exhibit indifferent equilibrium. Yet, no matter how hard one may try to do away with friction, it will never be true that the addition of the smallest possible weight sets in motion a balance 
that was in equilibrium. The intimate connection between rational principles and their material incarnation is possible only for systems in equilibrium. When a balance (or a pulley etc.) is set in motion, friction will always introduce extra factors that are beyond the reach of rational principles. In a letter to Giacomo Contarini we find Guidobaldo expanding on this. Particularly interesting is the fact that he stresses that although the addition of such a smallest weight does not set the balance in motion, this does not render the balance false..$^{92}$ This again betrays the role played by the rational principles: we know that this aberrant situation must be due to impediments such as friction, because we have the rational guarantee that the true cause of equilibrium is equality in weight. An analogue guarantee is missing for motion. All that we can absolutely be sure of is that we always need an extra finite force to break situations of equilibrium. Yet, this need not have concerned Guidobaldo unduly, since his precise analysis of equilibrium in machines is enough to show all the relevant structural characteristics of these machines.

It is important to note that Guidobaldo in the first place refers to the friction introduced by the turning of the machine around a fulcrum; i.e. even if we accepted the possibility of a vacuum, this would not fundamentally alter the situation. But thinking away the friction caused by the fulcrum would (in Guidobaldo's eyes) imply that the latter would no longer be a physical point, and hence that we would not be dealing with machines anymore - that we would quit the science of mechanics. It is clear from the preceding analyses that it is impossible to abstract from the physical nature of the fulcrum in Guidobaldo's conceptualization of mechanical phenomena.

To sum up: it is not that Guidobaldo does not acknowledge the fact that ideally true propositions can be violated through material hindrances, but that only under precise circumstances can these count as deviations from true principles; i.e. when these principles have already shown their empirical validity.

\section{The Dynamics of Stability}

It is well known that Galileo was not as disturbed by this lack of exact correspondence between principles and empirical situations, and that he resolutely chose to consider situations in which all friction was absent. What sets Guidobaldo apart from Galileo is that he refuses to go to these truly abstract applications of his concepts. ${ }^{93}$ This difference has nothing to do with the fact that Guidobaldo was part of a statical tradition that eschewed all dynamical notions, whereas Galileo would be the first truly to unite this with a dynamical tradition. Guidobaldo's analysis of equilibrium always has the following form: why is a balance in equilibrium/in motion? - because its centre of gravity (the seat of its dynamic tendency) coincides with/differs from the fulcrum, ${ }^{94}$ which through its stationary character exerts an opposing force that completely/only partly annihilates the tendency for motion. ${ }^{95} \mathrm{He}$ even goes as far as commenting on the speeds with which a balance will move to its position of equilibrium, depending on the relative position of its centre of gravity with respect to the fulcrum..$^{96}$ It is beyond doubt that Guidobaldo conceived of equilibrium as the result of the opposition of a dynamic force by another equally strong force. Both the static 
and the dynamic properties of the centre of gravity are essential to his conceptualizations, as was already clear from his comments on the Archimedean proof procedure for the law of the lever.

This is why it is highly misleading to construct the difference between the mixed science of mechanics and the natural philosophical theories of motion as a difference between statics and dynamics, as is often done. Some dynamical ideas (i.e. about the causes of natural motion) are necessarily present in mechanics, as these are part of the physical side of this mixed science, but the geometrical ratios that Guidobaldo is actually explaining are not at all about natural motion, but characterize the mechanical machines qua mathematical instruments.

That Guidobaldo could not have seen a substantial difference between a statical and a dynamical tradition is hence no case of anything like a doctrine of "double truth", ${ }^{97}$ but a consequence of the fact that weight functions in the same way in the contexts of both equilibrium and motion, the only relevant difference being the presence of extra friction. The works of Aristotle and Archimedes were too closely interwoven for him to see different traditions, ${ }^{98}$ whereas he strongly believed that the work of Jordanus was simply mistaken - the problem about Jordanus is not that he worked with dynamical notions, but that he missed the correct dynamics behind the different kinds of stability of a balance.

It is beyond the scope of the present paper to compare its results with the insights gathered in some of the previously cited literature on Guidobaldo's 'scientific project'. It is clear that we are in need of a sophisticated historiography to integrate these differently oriented analyses. Let me just stress what I take to be the most important lesson of my analysis. Even if we ignore most of the context in which Guidobaldo was operating, and if we concentrate our attention on how he conceptualized mechanical phenomena, a multi-layered picture emerges. It will not do to portray Guidobaldo as a strict Archimedean who tried to 'reconcile' his mechanics with Aristotelian notions. This is to forget how inherently problematic is the idea of someone's being strictly Archimedean, especially given the abstract character of the Equilibrium of planes. Whatever the story behind Guidobaldo's humanistic interest in restoring the ancient science of mechanics, it required a lot of creative and insightful interpretation. Many conceptual choices had to be made which could not be read off from the ancient sources, such as how to make sense of Archimedes's proof procedure in his proof of the law of the lever. Accordingly, we cannot simply identify different sources for our and sixteenth-century writers knowledge of (the history of) mechanics with distinct 'traditions'. In no way does this imply that we should do away with the historiographical notion of traditions, but it may serve as a warning that it is as often an explanandum as it is an explanans.

\section{ACKNOWLEDGEMENTS}

I wish to express my gratitude to the Archimedes project, which made available electronic versions of the writings of Guidobaldo that are discussed in the present paper (http://archimedes2.mpiwg-berlin.mpg.de/archimedes_templates). There is no doubt 
that this general availability will be an important factor in the further advancement of our understanding of the work of people such as Guidobaldo. I would also like to thank Giete Callaert for the excellent line drawings accompanying the present paper.

\section{REFERENCES}

1. P. Duhem, Les origines de la statique, i (Paris, 1905), 226.

2. R. Dugas, Histoire de la mécanique (Paris, 1950), 99; P. Costabel, Centre de gravité et équivalence dynamique (Paris, 1954), 10.

3. P. R. Rose, The Italian Renaissance of mathematics: Studies on humanists and mathematicians from Petrarch to Galileo (Geneva, 1975), chap. 10; S. Drake, "Introduction" in Mechanics in sixteenth-century Italy: Selections form Tartaglia, Benedetti, Guido Ubaldo, \& Galileo, transl. and annotated by S. Drake and I. E. Drabkin (Madison, 1969), 3-60.

4. Rose, op. cit. (ref. 3), 233; Drake, op. cit. (ref. 3), 48.

5. Drake, op. cit. (ref. 3), 46.

6. E. Gamba and V. Montebelli, Le scienze a Urbino nel tardo Rinascimento (Urbino, 1988); M. Biagioli, "The social status of Italian mathematicians", History of science, xxvii (1989), 41-95; D. Bertoloni Meli, "Guidobaldo dal Monte and the Archimedean revival", Nuncius, vii (1992), 3-34; G. Micheli, "Guidobaldo del Monte e la meccanica", Appendice II in Le origini del concetto di macchina (Florence, 1995); M. Henninger-Voss, "Working machines and noble mechanics: Guidobaldo del Monte and the translation of knowledge", Isis, xci (2000), 233-59.

7. Drake, op. cit. (ref. 3), 13.

8. Biagioli, op. cit. (ref. 6), 57.

9. Gamba and Montebelli, op. cit. (ref. 6).

10. Bertoloni Meli, op. cit. (ref. 6).

11. Micheli, op. cit. (ref. 6).

12. Henninger-Voss, op. cit. (ref. 6).

13. A useful summary of the landscape of sixteenth-century positions on this issue is provided in W. R. Laird, "The scope of Renaissance mechanics", Osiris, n.s., ii (1986), 43-69.

14. Gamba and Montebelli, op. cit. (ref. 6), part II, provides an exception but as the concept of centre of gravity is not further analysed there, the author misses an essential part of the fine-structure of Guidobaldo's conceptualization of mechanical phenomena.

15. Cf. especially M. Clagett, The science of mechanics in the Middle Ages (Madison, 1959), 3-23.

16. For some further historiographical reflections on the gradual process through which the distinction between statics and dynamics took its present-day shape, see A. Gabbey, "Between ars and philosophia naturalis: Reflections on the historiography of early modern mechanics", in J. V. Field and F. A. J. L. James (eds), Renaissance and revolution: Humanists, scholars, craftsmen and natural philosophers in early modern Europe (Cambridge, 1993), 133-45.

17. This is especially true with regard to Duhem's and Costabel's treatments of the status of the centre of gravity (Duhem, Les origins de la statique, ii (Paris, 1906), chaps. xv, xvi; Costabel, op. cit. (ref. 2)). Their criticisms clearly pinpoint in what sense Guidobaldo's understanding of this notion must differ essentially from a modern understanding. However, this need not be taken as a sign of Guidobaldo's incoherence (as they frequently suggest). It can also be taken as a warning notice that if we want to understand the coherence of his science on his own terms, we certainly will have to make sense of these differences.

18. N. Koertge, "Galileo and the problem of accidents", Journal of the history of ideas, xxxviii (1977), 389-408, p. 393. 
19. W. A. Wallace, Galileo and his sources: The heritage of the Collegio Romano in Galileo's science (Princeton, 1984), 241.

20. Guidobaldo del Monte, Mechanicorum liber (Pesaro, 1577); Le mechaniche, transl. by F. Pigafetta (Venice, 1581); In duos Archimedis Aequeponderatium libros paraphrasis (Pesaro, 1588). English translation of the first two books, when available, will be given from Mechanics in sixteenth-century Italy (ref. 3).

21. I am not aware of any other detailed study of Guidobaldo's paraphrasis. The only partial exception is Micheli, Le origini... (ref. 6), which has many references to Guidobaldo's understanding of specific aspects of Archimedes's treatise dispersed throughout the book.

22. For a sample of the modern literature on Archimedes, see E. J. Dijksterhuis, Archimedes (Princeton, 1987); A. G. Drachmann, "Fragments from Archimedes in Heron's Mechanics", Centaurus, viii (1963), 91-146; W. R. Knorr, Ancient sources of the medieval tradition of mechanics (Florence, 1982).

23. "Cùm itaquè supponat, nos exquisitam habere notitiam centri gravitatis." In duos... (ref. 20), 8.

24. Pappi Alexandrini Collectionis quae supersunt, ed. and transl. by F. Hultsch (Berlin, 1878).

25. "Haec igitur doctrinae centrobaricae summa esse videtur, cuius elementa ediscas, si Archimedis de aequilibriis libros et Heronis mechanica adieris...." Collectionis (ref. 24), 1035.

26. Mechanics (ref. 3), 244.

27. Collectionis (ref. 24), 1069; cf. the works of Dijksterhuis, Drachmann, and Knorr cited in ref. 22.

28. In duos... (ref. 20), 8-9; translation taken from Mechanics (ref. 3), 259.

29. This is explained in great detail in Archimedes's Method, to which Guidobaldo obviously had no access.

30. "etenim in his semper loquitur vel de gravibus simpliciter, veluti in primis tribus theorematibus; vel de magnitudinibus, ut in reliquis quinque quod quidem nomen tam planis, quàm solidis quibuscunque est comune, ut etiam ij, qui parùm in Mathematicis versati sunt, satis norunt." In duos... (ref. 20), 20.

31. In duos... (ref. 20), 19-21.

32. In duos... (ref. 20), 14-16.

33. E. Mach, The science of mechanics: A critical and historical account of its development, transl. by T. J. McCormack (LaSalle, 1974), 20.

34. "At verò quoniam demonstrationes ibi allatae indigent, quae Archimedes in sequenti sexta propositione demonstravit, idcirco demonstrationes illae huic loco non sunt oportunae." In duos... (ref. 20), 59. (Guidobaldo is referring to demonstrations of some propositions in his Liber mechanicorum.)

35. In duos... (ref. 20), 55-58.

36. "Quocumque enim modo eadem gravia sese habent, eodem semper modo in eius gravitatis centro gravitant." In duos... (ref. 20), 56.

37. In duos... (ref. 20), 9-11; 43-44.

38. Note that this involves a subtle shift of reasoning on Guidobaldo's part. To make this point, he turns to Commandino's definition of centre of gravity, which Guidobaldo always presents as completely equivalent to Pappus's definition (he calls it a "descriptionem" of the notion, rather than a definition, presumably implying that Commandino gives a further explanation of how we should understand the actual definition, which is due to Pappus). Commandino's definition, however, nowhere mentions suspension, but only states that the parts of the body on all sides of its centre of gravity will have equal moment ("Centrum gravitatis uniuscuisque solidae figurae est punctum illud intra positum, circa quod undique partes aequalium momentorum consistent", In duos... (ref. 20), 9). Pappus's definition, with its emphasis on suspension, is rather ill-suited to establish this cosmological connection, since it seems improper to think of the role of the centre of the universe as a point of suspension. 
39. "Quare dum asseritur, grave quodcumque naturali propensione sedem in mundi centro appetere, nil aliud significantur, quàm quòd eiusmodi grave proprium centrum gravitatis cum centro universi coaptere expetit, ut optimè quiescere valeat.... Ex iis omnibus, quae hactenus de centro gravitatis dicta sunt, perspicuum est, unumquodque grave in eius centro gravitates propriè gravitare.... Praeterea quando aliquod pondus ab aliqua potentia in centro gravitatis sustinetur; tunc pondus statim manet, totaquè ipsius ponderis gravitas sensu percipitur." In duos... (ref. 20), 10.

40. "Quoniam scilicet recta linea $\mathrm{AB}$ eas [magnitudines $\mathrm{AB}$ ] coniungit ; ideo Archimedes considerat unam tantùm esse magnitudinem.... Neque magis una est magnitudo quadrilaterum, pentagonum, cubus, \& huiusmodi aliae, quam sit magnitudo, quae componitur ex magnitudinibus $\mathrm{AB}$ unà cum linea $\mathrm{AB}$. quòd si est una tantùm magnitudo, ergo unum habet centrum gravitatis." In duos... (ref. 20), 43.

41. P. L. Rose and S. Drake, "The Pseudo-Aristotelian questions of mechanics in Renaissance culture", Studies in the Renaissance, xviii (1971), 65-104.

42. G. Micheli, Le origini... (ref. 6), especially chap. 3, is a recent and erudite study aimed at a more precise understanding of the Mechanical problems, which moreover pays much attention to Renaissance commentaries on the work.

43. Aristotle, Minor works, transl. by W. S. Hett (Cambridge, MA, 1963), 333. I will use this twentiethcentury translation, without paying attention to the sixteenth-century translations and paraphrases, as the differences are irrelevant to my purposes. See Micheli, Le origini... (ref. 6), chap. 3, for discussions of some of these differences.

44. Aristotle, Minor works (ref. 43), 337.

45. I think it is clear from pseudo-Aristotle's own explanation that this force is not to be identified in general with the action of a weight, but with a tangentially applied force generating the motion of the radius and hence the 'nature' of the circle. All this is part of a general investigation of the properties of a circle, not of the behaviour of weights. Only at the end of his explanation, when actually answering the first problem, does pseudo-Aristotle identify the equal force on both a large and a small radius with the weight in a balance. It is of course a conspicuous aspect of a balance that its arms are placed horizontally, and that the action of the weight is thus indeed working tangentially. The general properties of a circle can thus be invoked to explain the behaviour of a balance near equilibrium (and this is all the author is interested in at this point).

46. Aristotle, Minor works (ref. 43), 341-3.

47. Aristotle, Minor works (ref. 43), 353.

48. Aristotle, Minor works (ref. 43), 353.

49. "Punctum autem illud, quod Archimedes accipit, unde sumuntur distantiae, ex quibus gravia suspenduntur, ... Aristoteles centrum appellat." In duos... (ref. 20), 24.

50. Yet it must be noted that it is not by accident that Guidobaldo most probably found the inspiration for his explanation in the Mechanical problems, where the parallelogram rule for the composition of motion is expounded and moreover lies at the centre of the explanatory structure. An important difference remains that Guidobaldo would have to consider the tangential force/motion as the resultant of the perpendicular free force (i.e. the weight) and the constraining force, which is normal to the circumference, whereas the Greek author considers the circumference itself as the result of the composition of motions which result from a force directed towards the centre and a tangentially applied force.

One reason why one may suppose that Guidobaldo never consciously analysed the details of such decomposition is that it would almost directly have led him to the correct solution of the inclined plane problem. The main reason why he did not take this route, and instead adopted Pappus's treatment of the inclined plane, is probably that he conceived an inclined plane as a wedge upon which a body is forced to move. As Guidobaldo himself did not include Pappus's proof in his own treatise (it was only added in Pigafetta's translation), as his references to Pappus's 
treatment are rather sloppy (the balance involved in Pappus's proof has e.g. its fulcrum in the point of contact between the body and the inclined plane, whereas the lever to which Guidobaldo wants to assimilate the wedge has its fulcrum in the tip of the wedge), and as he only uses the qualitative result that more force is needed as the plane is more oblique (in conformity with his belief that no exact proportions could be given for problems involving motion - see the last section of this paper), I think we can safely assume that he did not pay close attention to the conceptualization of the inclined plane problem. The references to Pappus rather seem to be added to justify his inclusion of the wedge and the screw in his mechanical treatise. Accordingly, I will not further treat the inclined plane in the present paper. Revealing questions can be posed about Guidobaldo's decision to refer to it in his treatise, but these fall outside the limited perspective I have adopted here.

51. "Supponit autem Archimedes hoc postulatum respiciens fortasse ad ea, quae Aristoteles in principio quaestionum mechanicarum ostendit, ubi colligit Aristoteles idem pondus celeriùs ferri, quò magis à centro distat...." In duos... (ref. 20), 26.

52. Drake, op. cit. (ref. 3), 15.

53. "demonstratum est enim in Archimedis libro $\pi \varepsilon \rho \iota \zeta \jmath \gamma \omega v$ sive de stateris et in Philonis Heronisque mechanicis, a maioribus circulis superari minores circulos, si circa idem centrum conversio eorum fiat." Collectionis (ref. 24), 1069.

54. Mechanicorum liber (ref. 20), 1v; Mechanics (ref. 3), 259.

55. I will not give references to the places where the relevant passages in Tartaglia, Cardano, and Jordanus can be found, since these are already noted in the translation of Guidobaldo's treatise in Mechanics (ref. 3).

56. A third argument described by Guidobaldo does not truly involve the notion of positional gravity.

57. The cogency of this critique was denied by Duhem, who stresses that according to Jordanus the positional gravity has to be calculated for an arc smaller than any assigned value (Duhem, op. cit. (ref. 1), 215).

58. Mechanicorum liber (ref. 20), 26v; Mechanics (ref. 3), 290.

59. Mechanicorum liber (ref. 20), 26v; Mechanics (ref. 3), 290.

60. Mechanicorum liber (ref. 20), 20r; Mechanics (ref. 3), 282.

61. It is true that the present explanation introduces some problems of its own; it is especially hard to understand what happens with the bodies' tendencies to descend at the point when their centre of gravity coincides with the centre of the world. This situation reappears in Fermat's discussion of the geostatic question, and shows its problematic character in that context.

62. See the transcription of a letter of Guidobaldo to Pigafetta in an appendix to Micheli, op. cit. (ref. 6).

63. Le mechaniche (ref. 20), 28r; Mechanics (ref. 3), 294.

64. Mechanicorum liber (ref. 20), 5v; Mechanics (ref. 3), 262.

65. Cf. Duhem, op. cit. (ref. 17); Costabel, op. cit. (ref. 2); S. Roux, "Cartesian mechanics", in C. R. Palmerino and J. M. M. H. Thijssen (eds), The reception of the Galilean science of motion in seventeenth-century Europe (Dordrecht, 2004), 25-66.

66. This is especially so if we take into account that he had earlier criticized Tartaglia et al. because their arguments concerning the differences in positional gravity would imply a change in centre of gravity with the inclination of a balance.

67. Le mechaniche (ref. 20), 28r; Mechanics (ref. 3), 295.

68. I claimed in the introduction ( $c f$. ref. 17 and the accompanying text) that some of the conclusions of Duhem and Costabel could be used as a kind of hermeneutic benchmarks, because they allow us to pinpoint in what respects Guidobaldo's conceptualization of mechanics is essentially different from a modern one. Let me quickly summarize these conclusions, and leave it to the 
reader to compare them with the foregoing discussions. Both Duhem and Costabel make a lot out of the presumed fact that Guidobaldo's conception of centre of gravity had to be incoherent because it involved both the definition due to Pappus, and the one due to Albert of Saxony. The first presumably involves parallel lines of descent (because, as we saw, this is a precondition for indifferent stability), whereas the second essentially involves the centre of the universe (it is broadly speaking the idea that in any body there is one point which strives to unite itself with the centre of the universe), and hence brings with it convergence of lines of descent. On this ground, they criticize Guidobaldo on two scores: that he does not realize this incoherence, and that he cannot possibly overcome it. According to them, this incoherence could only be overcome by leaving behind the overtly physical connotations of both definitions, and by introducing a purely geometrical definition. Such a definition would allow the centre of gravity (which would become an ill-suited name for the concept) to play its truly fruitful role: to be a centre of dynamical equivalence; i.e. one can derive from this geometrical definition that it is the point where one can conceive all the mass of a system of bodies to be concentrated and the geometrical resultant of all the forces on these bodies to be applied. If we take these forces to be forces of weight, and if these are considered to be parallel, then it follows that we can always replace the system of bodies by its centre of gravity. That we have indifferent equilibrium if we hold a body in its centre of gravity is merely a physical consequence of this fact, but it is no part of the defining characteristics of the concept.

69. "Riduco le cinque machine alla leva, è vero, ma non però riduco la bilancia alla leva, essendo che esse siano una med.ma cosa e fra loro non vi è altra differenza, se non che con la bilancia si considerano li pesi, e con la leva si considerano la forza e il peso insieme...." Quoted in Micheli, op. cit. (ref. 6), 161.

70. Drake's translation in Mechanics (ref. 3) skips almost all the proofs of the propositions concerning the lever, hence actually hiding the transformations that govern Guidobaldo's understanding of the lever.

71. Already in Proposition 5 on the balance Guidobaldo states that suspended weights ("pondera") have gravity ("gravitate") in proportion to the distance from the fulcrum. The closeness to our notion of static moment is explicit in Commandino's version of the definition of centre of gravity. It is important, however, to keep in mind that static moment depends not only on the length of the lever arm, but also on the direction of the applied force.

72. Mechanicorum liber (ref. 20), 42r; again a passage not included in Drake's translation.

73. Guidobaldo explicitly notices that in his pulley systems "the power will always move the weight as with a lever parallel to the horizon". Mechanicorum liber (ref. 20), 77r; Mechanics (ref. 3), 311.

74. Duhem, op. cit. (ref. 1), 219-23.

75. Mechanicorum liber (ref. 20), 108r; Mechanics (ref. 3), 318.

76. Compare especially with the discussions at Mechanicorum liber (ref. 20), 29v-30r; Mechanics (ref. 3), 293.

77. "tunc eademmet potentia, vel in $\mathrm{F}$, vel in $\mathrm{T}$ constituta idem pondus $\mathrm{k}$ sustinere poterit; cùm semper in cuiuscunque: extremitate scytalae ponatur, ab eodem centro $\mathrm{C}$ aequidistans fuerit, ac secundum eandem circumferentiam ab eodem centro aequaliter semper distantem perpensionem habeat." Mechanicorum liber (ref. 20), 109r.

78. At least, I have not been able to locate other places in Guidobaldo's writings where he would directly apply the insight that it is only the perpendicular component that must be taken account. Proposition 5 of the section on the lever in the Mechanicorum liber is certainly not a case, as is claimed by Montebelli (Gamba and Montebelli, op. cit. (ref. 6), 239-40). One only has to notice that Guidobaldo nowhere considers the projection of the arm on which the power is applied to see the inappropriateness of the figure that is provided by Montebelli (his Figure 14). Guidobaldo in this proposition is not discussing the need to project the lines of force on a perpendicular arm, 
but the place where we should consider the force of the weight to be applied to the lever arm (which need not result in a perpendicular projection).

79. Henninger-Voss, op. cit. (ref. 6), 255.

80. I borrow the apt expression "bringing into operative act" from Henninger-Voss, op. cit. (ref. 6), 247, which, notwithstanding the confusion just pointed out in the text, is undoubtedly the best analysis of the hybrid nature of this double exploitation.

81. Cf. especially In duos... (ref. 20), 48, where Guidobaldo stresses the fact that centre of gravity is a mathematical notion, defined for mathematical objects, which allows its introduction in the Archimedean proofs of Propositions 6 and 7.

82. Duhem, op. cit. (ref. 1), 209-26; Drake, op. cit. (ref. 3), 44-48; Rose, op. cit. (ref. 3), 233.

83. It is noteworthy that in Guidobaldo's own preface to the Mechanicorum liber, which stresses both the utility and the nobility of mechanics, he has only a scornful remark for Jordanus's "disastrous errors"; whereas Pigafetta's preface, which is almost exclusively devoted to the utility of mechanics, has a much more friendly reference to Jordanus, "who wrote of the science of mechanics" and "began to resuscitate it somewhat". (Mechanicorum liber (ref. 20), unnumbered preface; Le mechaniche (ref. 18), unnumbered preface; Mechanics (ref. 3), 246, 252. For an analysis of the differences between the Latin work and its vernacular translation, see HenningerVoss, op. cit. (ref. 6).) Guidobaldo's gibe occurs in the context of his stressing that he has tried to build up his work "from it foundation to its very top" — the most important problem with Jordanus is clearly not that he had made some easily correctable errors, or that he had introduced different concepts, but that he threatened these essential foundations.

84. Cf. e.g. the letter to Contarini cited in Gamba and Montebelli, op. cit. (ref. 6), 86.

85. The structure of the mixed, middle, subordinate, or subalternate sciences has received a considerable amount of attention in the literature. $C f$. e.g. R. D. McKirahan Jr, "Aristotle's subordinate sciences", The British journal for the history of science, xi (1978), 197-220; Wallace, op. cit. (ref. 19), chap. 3; J. G. Lennox, "Aristotle, Galileo, and 'mixed sciences"”, in W. A. Wallace (ed.), Reinterpreting Galileo (Washington, DC, 1986), 29-51; W. R. Laird, "Robert Grosseteste on the subalternate sciences", Traditio, xxxiii (1987), 147-69; P. Dear, Discipline \& experience: The mathematical way in the Scientific Revolution (Chicago and London, 1995), chap. 2.

86. That any body has a centre of gravity; that it descends according to its centre of gravity; etc.

87. Tartaglia, Quesiti et inventioni diverse (Venice, 1546), 76-78; transl. from Mechanics in sixteenthcentury Italy (ref. 3), 106-7.

88. Mechanicorum liber (ref. 18), unnumbered preface; Mechanics in sixteenth-century Italy (ref. 3), 245.

89. M. Henninger-Voss, "How the 'new science' of cannons shook up the Aristotelian cosmos", Journal of the history of ideas, 1xiii (2002), 371-97, p. 382.

90. Le mechaniche (ref. 20), 28r; Mechanics (ref. 3), 295.

91. That this claim is not due to the fact that he "refused to countenance the use of insensibilia in mechanics, because they were not susceptible of precise mathematical definition" (as is claimed by Rose, $o p$. cit. (ref. 3), 233) is proven by his discussion of the argument concerning smallest angles.

92. "La materia fa qualche resistenza ... la qual [materia] vuol la parte sua ancor lei, e quanto sono più grandi in materia tanto più resiste, sì come si provo tutto il giorno nelle libre che, per picole $\mathrm{e}$ guiste che le siano e che habbino pesi da tutte due le bande eguali e giusti, non di meno a un di loro se gli potrà metter sopra et aggiunger un peso di tanto poco momento, come un minimo pezzolino di carta che la bilancia starà senza andar giù da detta parte, né per questo la bilancia sarà falsa ; dove è da considerare che la resistanza che fa la materia lo fa quando si hanno da mover i pesi e non quando se hanno da sostenere solamente, perché all'hora l'instrumento non si move né gira; e con queste considerationi la troverà sempre che l'esperienza e la demonstrazione andaranno sempre insieme." (Quoted in Gamba and Montebelli, op. cit. (ref. 6), 76.) 
93. This does leave open the question of the grounds on which Galileo nevertheless chose to take the steps that Guidobaldo consciously refused to take.

94. The formulation is a little too concise: it is not necessary that the centre of gravity coincides with the fulcrum; it is enough that it lies on a straight line connecting the fulcrum with the centre of the world - this is of course exactly the difference between on the one hand indifferent and on the other hand stable and unstable equilibrium.

95. The proof of the first proposition in the Mechanicorum liber, which is skipped in Drake's translation, provides a nice illustration of this mode of argumentation.

96. Mechanicorum liber (ref. 20), 24v; Mechanics (ref. 3), 287.

97. Biagioli, op. cit. (ref. 6), 65.

98. I already quoted Drake's judgement that this was "a curious theory of the history of mechanics". Knorr, op. cit. (ref. 22), provides convincing arguments for the exciting thesis that this might actually be the best history of mechanics available. He shows how the medieval so-called dynamical treatments of the balance in all probability derive directly from a lost work of Archimedes, pre-dating the Equilibrium of planes and the introduction of the concept of centre of gravity, and he adds the suggestion that Archimedes's interest in this kind of problems might have been triggered by the pseudo-Aristotelian treatment (ibid., 100-2). It hence appears that what most historians of science have construed as two entirely different traditions actually have a common root in closely related efforts that took place in one and the same context. 
